\title{
Growth and yield of lodgepole pine stands disturbed by mountain pine beetle in the Lower Foothills of Alberta
}

\author{
by W. Richard Dempster ${ }^{1}$ and Sharon Meredith ${ }^{2}$
}

\begin{abstract}
Changes in the structure and dynamics of lodgepole pine stands following the 2006 outbreak of mountain pine beetle in western Alberta were investigated by monitoring attacked permanent sample plots over the following decade and projecting future stand development with locally validated growth models. Results suggest that a wide range in growth and yield of attacked stands is likely, with projected impacts varying from minor and inconsequential modifications to full stand replacement. Severely disturbed stands are unlikely to naturally regenerate to pine. The degree to which timber production is naturally restored in such stands will depend to a large extent on the amount and composition of non-pine advance growth and regeneration. Variation in attack severity and tree species composition will, in the absence of clearcutting following disturbance, result in increased diversity in stand and forest structure. Recommendations are made for scheduling salvage and restoration operations to ameliorate losses in timber supply.
\end{abstract}

Keywords: mountain pine beetle, lodgepole pine, growth and yield, forest regeneration, silviculture, stand structure, forest disturbance, forest modeling

\section{RÉSUMÉ}

Nous nous sommes intéressés aux changements de structure et de dynamique dans des peuplements de pin lodgepole à la suite de l'épidémie de 2006 du scolyte du pin dans l'Ouest de l'Alberta. À cette fin, nous avons suivi l'évolution des placettes permanentes tout au long de la décennie qui a suivi l'épidémie et projeté l'évolution subséquente du peuplement à l'aide de modèles de croissance validés régionalement. Nos résultats laissent entrevoir que la croissance et les rendements peuvent varier considérablement selon les peuplements attaqués; les effets prévus variaient ainsi de mineurs ou nuls jusqu'au remplacement complet du peuplement. Les peuplements ayant été fortement perturbés ont peu de chances de se régénérer avec du pin. La restauration naturelle de la production ligneuse dépendra en grande partie de la quantité de régénération préétablie et de sa composition en essences autres que le pin. C'est le niveau de dommage et la composition du peuplement original qui permettront d'accroître la diversité dans la structure des peuplements et de la forêt s'il n'y a pas de coupe rase après la perturbation. Il serait recommandable de prévoir des opérations de récupération et de reboisement si l'on souhaite diminuer les pertes d'approvisionnement en bois.

Mots-clés: scolyte du pin, pin lodgepole, croissance et rendement, régénération forestière, sylviculture, structure de peuplement, perturbation forestière modélisation forestière

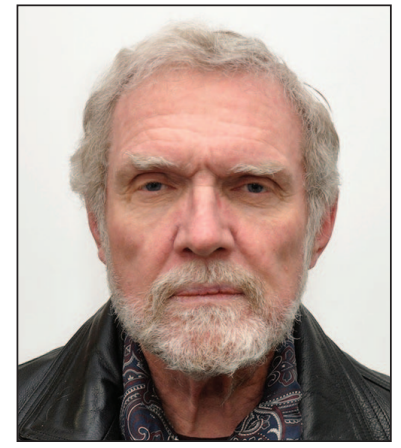

W. Richard Dempster

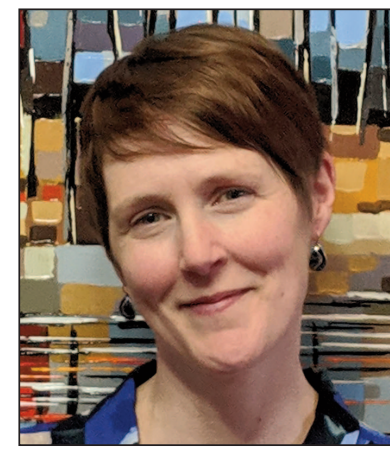

Sharon Meredith

\section{Introduction}

Mountain pine beetle (Dendroctonus ponderosae Hopkins) is endemic to Alberta (Powell 1966), but until recently its spread and importance have been constrained by climatic conditions. The ongoing, unprecedented outbreak in Alberta since 2006, in part due to a significant climate-induced range expansion (Carroll et al. 2017), has resulted in increased interest in understanding how stands will respond after attack. Much work has been done on forecasting regeneration and growth and yield of lodgepole pine ((Pinus contorta Dougl. ex Loud. var. latifolia Engelm.) following normal clear-cut harvesting in Alberta (e.g., Huang et al. 2009; Dempster and Meredith 2014). However, with exceptions noted below, local quantitative information is generally scarce for forecasting timber pro-

\footnotetext{
${ }_{1}^{1}$ Research and Development Associate, Forest Growth Organization of Western Canada, fRI Research, Hinton AB T7V 1V3, Canada; Corresponding author email: wr.dick.dempster@gmail.com

${ }^{2}$ Past Director, Forest Growth Organization of Western Canada, fRI Research, Hinton AB T7V 1V3, Canada
} 
ductivity following attack. This information is essential to support decision-making for effectively prioritizing salvage operations, regulating allowable-cuts, and managing the forest for long term timber supply.

Early insights into the potential for lodgepole pine regeneration following mountain pine beetle (MPB) attack in Alberta were provided by McIntosh and Macdonald (2013), who simulated attack in Upper Foothills stands by killing trees with glyphosate. They reported low levels of recruitment from advance regeneration and sown seed, and a scarcity of suitable seedbeds, suggesting low potential for recovery by advanced growth or regeneration of pine. Steinke (2019) later found that less than half of 33 sites, subjected to severe attack in west-central Alberta, had any evidence of natural pine regeneration.

The longer-term impacts of an earlier MPB outbreak which occurred in Waterton Lakes National Park in southwestern Alberta were studied by Axelson et al. (2018). The outbreak resulted in variable levels of mortality of mature lodgepole pine. Nearly 30 years after peak MPB activity, lodgepole pine was no longer the dominant overstorey species, with increases in non-pine conifers (Douglas fir (Pseudotsuga menziesii var. glauca Franco), white spruce (Picea glauca (Moench) Voss), and hardwoods (trembling aspen (Populus tremuloides Michx.), balsam poplar (Populus balsamifera L.). Density of understorey saplings and smaller regeneration increased in the last 10 years. It was dominated by non-pine conifer and broadleaf species, with lodgepole pine nearly absent. The MPB outbreak resulted in greater heterogeneity in composition and structure, with multiple successional trajectories and reduced MPB susceptibility. Following the larger recent outbreak in Alberta, Oboite and Comeau (2018) demonstrated that advance regeneration of both black and white spruce responds in growth and can potentially replace killed pine in the canopy.

Beyond Alberta, and especially in British Columbia, a large amount of research into regeneration, growth and treatment following MPB was reviewed and synthesized by Mitchel (2005), Dhar and Hawkins (2011), and Dhar et al. (2016). The latter paper explored the aftermath and ramifications of the outbreak in B.C. in terms of stand dynamics, mid-term timber supply and ecosystem resilience, and concluded that:

- There are sufficient amounts of residual structure and evidence of stand recovery to significantly contribute to midterm timber supply;

- As a result of the epidemic, stands are more structurally and compositionally diverse, and more ecologically resilient; and,

- Only a small percentage of non-salvaged stands require intervention to achieve mid-term timber supply goals.

Hawkins et al. (2012) noted that, after the peak of the epidemic in B.C., most attacked stands had sufficient trees of commercially preferred species to be considered stocked, and could reach merchantable volumes within 30 years, albeit moving towards a mixed species and uneven-aged condition. Similarly, Campbell and Antos (2015) concluded that most stands in the boreal forest of B.C. could be left to recover naturally without major long-term impacts on ecological and socioeconomic values. However, they also noted that their results starkly contrasted with those of McIntosh and Macdonald (2013) for Alberta. They suggested that it may be premature to make generalizations about the resilience of boreal forests to MPB outbreaks, and there could be substantial variability in the capacity of stands to recover. Observations of non-salvaged natural stands in the Flathead Valley of southeastern B.C. by Amoroso et al. (2013) nearly 30 years after an intense epidemic, also discourage premature generalization. Recovery involved frequent release of surviving trees; but strong ingress of regeneration did not occur until 10 to 20 years after attack i.e. at a stage of development that is only now being reached in Alberta. A study of seed release in B.C. lodgepole pine forests after MPB attack (Teste et al. 2011) urged for caution in assuming adequate regeneration from seed, and concluded that fire or anthropogenic disturbances need to occur to create receptive seedbeds shortly after tree mortality, before the seed banks are lost, in order to obtain normal levels of regeneration.

A common theme in much of the literature quoted above from B.C., echoed in Alberta by Axelson et al. (2018), is the progression towards a mixed species and uneven-aged stand condition that may be more ecologically resilient than preattack stands. Coates and Burton (1997) advocated a gapbased approach to developing innovative silvicultural systems as an alternative to prescribed homogeneity optimizing tree growth. It appears that the B.C. epidemic produced some of the associated benefits. However, several studies in Alberta have demonstrated the benefits to the natural regeneration, growth and health of lodgepole pine where stands were harvested and scarified to produce even-aged conditions e.g., Johnstone (1976), Huang et al. (2004), Landhäusser (2009), and Dempster (2017).

Mitchel (2005) pointed out that no one regeneration method will be applicable across all sites, and that managers will need to apply a variety of methods depending on the percentage of kill by MPB, original stand composition, natural disturbance pattern, and soil moisture and nutrient regimes. Flexible silvicultural systems accommodating variable regeneration periods, uneven-aged forest types and compositional and structural variability, such as the Swiss or Baden Femelschlag (irregular shelter-wood system), have not been widely applied in North America, but have long been used elsewhere (Troup 1952), and may represent opportunities for managing post-attack stand conditions.

In Alberta, a network of existing permanent sample plots (PSPs) distributed over the geographic range of lodgepole pine was excluded from harvesting in 2007 to allow assessment of stand development following the outbreak of mountain pine beetle (MPB) which commenced in western Alberta in 2006. The long-term intent of this initiative, supplemented by additional PSPs installed in attacked stands, is to monitor the impact of MPB infestation on tree mortality, growth of residual trees, tree regeneration, and development of nontree vegetation, in attacked stands that have not been subject to salvage or other management interventions. Baseline measurements were made before the initial outbreak of MPB. Plots were assessed for MPB disturbance, and a sub-set of attacked plots were re-measured at least once $6-10$ years following attack.

The attacked PSPs that were available for this study are located between latitudes $54.04^{\circ}$ to $54.74^{\circ} \mathrm{N}$ and longitudes $116.30^{\circ}$ to $119.00^{\circ} \mathrm{W}$, in the Lower Foothills natural subregion of Alberta. Sites are predominantly mesic in soil moisture regime and medium in soil nutrient regime, as is typical 
for fire-origin lodgepole pine stands growing in West-central Alberta (Beckingham et al. 1996). Stands are mature and generally similar with respect to age.

The limited sample size and range of site and stand conditions represented in attacked and monitored plots did not facilitate a comprehensive assessment of factors influencing MPB attack and tree mortality. ${ }^{1}$ However, a wide range of attack severity was observed. This provided an opportunity to examine changes in stand structure and dynamics over the decade following disturbance, how these changes relate to the severity of MPB attack, and what levels of future growth and yield might be expected. Specifically, the following null hypotheses were tested:

1. Attack severity: stand and site factors have no effect on attack severity;

2. Stand dynamics: attack severity does not affect the mortality, fall-down, growth or ingress of lodgepole pine trees, or the ingress of other species;

3. Post-attack stand structure: attack severity has no effect on the post-attack tree, sapling, or regeneration densities of pine or other tree species;

4. Projected growth and yield:

a. MPB attack will not affect the long term growth and yield of coniferous trees left standing after attack;

b. Saplings and regeneration will not contribute to the future growth and yield of attacked stands.

Throughout this paper "trees" refers to stems $>9 \mathrm{~cm}$ diameter breast-height (DBH), "saplings" to stems $>1.3 \mathrm{~m}$ in height and $<9 \mathrm{~cm} \mathrm{DBH}$, and "regeneration" to stems $>0.3$ $\mathrm{cm}$ and $<1.3 \mathrm{~m}$ in height.

\section{Materials and methods}

Data were obtained from 65 PSPs (sampling units) within 17 attacked stands (experimental units). Both pre-attack (baseline) and post-attack data were available for four PSPs in each stand, except for one stand which had complete post-attack data in only one PSP. All PSPs otherwise met the following conditions:

- At least 50 live lodgepole pine trees per plot present before disturbance, with pine as the leading species (plots were typically 0.1 ha in area);

- Well buffered from stand edge (most of the plots were located in stand areas of about 9 ha reserved from harvesting or salvage);

- Available pre-attack detailed baseline measurements with all trees tagged, uniquely numbered, and assessed for species, height, diameter, condition and health;

- Sufficient and appropriate pine trees measured for age to allow calculation of site index;

- Plots periodically visited during the outbreak to identify trees attacked by MPB;

- MPB attack confirmed within the plot or adjacent portion of the stand prior to the year 2010;

- Re-measured in detail at least once a minimum of 6 years after initial attack (the majority of plots were re-measured $8-10$ years after attack);

- All trees tagged in the baseline measurement accounted for in the re-measurement; and,

\footnotetext{
${ }^{1}$ See also Supplementary Material: Interim technical report - tree mortality rates following attack by mountain pine beetle in Alberta, May 8, 2017
}

- Trees, saplings and regeneration of all tree species assessed in the re-measurement, with $100 \%$ sampling of trees, and sub-sampling of saplings and regeneration.

Attack severity was assessed as the percentage of lodgepole pine trees which had pith nodes created by MPB documented at any time from baseline to final measurement. Although the limited sample size and range of site conditions represented by the data were not expected to allow a comprehensive assessment of factors influencing attack severity, the extent to which variation in attack severity could be explained by stand and site variables and MPB productivity was investigated. Local MPB productivity was assessed at the stand level by compilation of data from Alberta government "r-value" surveys conducted within $15 \mathrm{~km}$ of each stand between 2009 and 2015. The r-value is an index of beetle productivity used in Alberta, and is defined as the ratio of surviving offspring to parent attacks. It is determined by removing a standard area of bark from infected trees and counting the number of attack initiations and the number of surviving offspring prior to beetle emergence (Carroll et al. 2017). Lodgepole pine site index, defined as the top height of the 100 largest DBH trees ha ${ }^{-1}$ at 50 years breast-height age (Huang et al. 2009), was computed at the plot level to provide a continuous measure of site quality.

The following changes and dynamics occurring between baseline and post-attack measurements were investigated for lodgepole pine trees:

- Mortality and fall-down, measured in terms of stems and basal area ha ${ }^{-1}$, and based on trees that were tagged and alive before attack;

- Growth, measured as the increment in quadratic mean $\mathrm{DBH}$, average height and basal area $\mathrm{ha}^{-1}$ of those trees alive before attack, that were still surviving after attack;

- Ingress, i.e., post-attack density and basal area stocking of trees that were not present (or were $<9 \mathrm{~cm} \mathrm{DBH}$ ) at the pre-attack measurement.

Tree ingress in incidental hardwoods, black spruce and shade tolerant conifers (white spruce and balsam fir), and changes in non-tree vegetation, were also investigated.

Measurement procedures followed standards established for government and industrial sample plots in Alberta (Anon. 2015). Plot sizes averaged $1164 \mathrm{~m}^{2}$, ranging from 396 to $2052 \mathrm{~m}^{2}$. The variable plot sizes were originally adopted to limit excessive sampling, but ensure a minimum 100 live trees ha- ${ }^{-}$. Each PSP contained a sapling sub-plot, averaging $84 \mathrm{~m}^{2}$, and four $10 \mathrm{~m}^{2}$ regeneration sub-plots. Consistent measurements of saplings and regeneration were not available for most plots before disturbance, so analysis of changes in these components was not possible. However, consistent post-attack measurements of saplings and regeneration were available for all 17 stands, allowing examination of how these components influenced subsequent growth and yield. Postattack regeneration and dropped-cone densities were sampled on the regeneration sub-plots. Data on changes in nontree vegetative cover, also sampled on the regeneration sub-plots, were available and analyzed for 9 of the 17 stands.

Two growth models were investigated for projecting growth and yield: GYPSY (Huang et al. 2009) and MGM (Bokalo et al. 2013). Both models are deterministic and were developed empirically, primarily from Albertan permanent sample plot data, for pure and mixed generally even-aged 
stands of Alberta's four main tree species: lodgepole pine, white spruce (Picea glauca (Moench) Voss), black spruce (Picea mariana (Mill.) B.S.P.) and trembling aspen (Populus tremuloides Michx.). Both output summaries including yield tables and charts portraying averages for above ground volumes and other stand parameters.

GYPSY (Growth and Yield Projection System) is a standlevel model developed and approved by the Alberta Ministry of Agriculture and Forestry to support timber supply analysis and forest management planning, and to provide a link between post-harvest regeneration performance and future growth and yield, as required by the Reforestation Standard of Alberta (Alberta Agriculture and Forestry 2020). It utilizes a series of sub-models for top height, percent stocking, density (spatial and non-spatial), basal area increment (spatial and non-spatial) and total and merchantable volume.

MGM (Mixedwood Growth Model) is a deterministic, distance-independent, individual tree growth model developed by the University of Alberta for the western Canadian boreal forest. It is designed to model yield for simple or complex multi-species, multi-cohort stands. The model utilizes individual tree growth (height increment and diameter increment) and survival functions to project a list of trees into the future. It includes sub-models for juvenile, mid-rotation and mature trees. Site index and competition from other trees are key drivers of the individual-tree growth functions. In the present study, the model was initialized by input in the form of tree lists including species, diameters, heights and expansion factors, plus information on site index and age. The stand visualization system (McGaughey 2018) built into MGM was utilized to provide visual representations of changes in stand structure.

Preliminary comparisons between GYPSY and MGM showed minimal differences in projections of densities and volumes of conifers and hardwoods over a 50-year postattack period. MGM was found to be slightly more conservative in predicting survival and growth than was GYPSY, and its individual tree functions facilitated projection of the more complex stand structures arising following disturbance by MPB. Subsequent projections in this study were therefore made entirely with MGM. They were made for the period from 10 to 50 years after attack. Longer projections were considered unreliable because ages of the residual stands by this time tended to exceed the maximum ages (160 - 180 years) of sample plots used in development of the growth and yield model.

Standard least squares regression analyses and analysis of variance (ANOVA), and associated effect tests (SAS Institute Inc. 2002), were used to examine variation in attack severity, and the relationships of mortality, growth, ingress, and postattack structure to attack severity and to other continuous stand and site variables. Multiple response fitting (MANOVA) and matched pairs analysis techniques were applied for repeated measures analyses to examine changes between baseline and post-attack measurements. MANOVA was also used to test for differences between model simulations, which involved repeated projections over time. These analyses were all based on data aggregated to the stand (experimental unit) level, with the exception of an initial assessment of differences between stands relative to withinstand variation.

\section{Results}

Table 1 lists means and standard deviations of variables representing lodgepole pine conditions before and after MPB attack in each of the 17 stands studied. Attack severity percent, and pre-attack age, top height, site index, DBH, basal area and stems ha-1 all showed between-stand differences that were statistically significant (probability of chance occurrence 0.05 or less).

\section{Attack severity}

The effect of stand and site conditions on attack severity percent are summarised in Table 2. The bolded $P r o b>F$ values listed for effect tests highlight those variables where the null hypothesis (that they have no effect on severity) was indicated to be untrue. Trends of severity with each statistically significant variable are shown as positive (i.e., increasing) or negative (i.e., decreasing). Results suggest that stand and site factors had a significant effect on attack severity. Severity was most strongly affected by local MPB productivity (r-value). It increased with years since initial attack, and with pre-attack site index, top height and basal area. However, the effects of years since attack and basal area were masked when r-value was included in the model. Severity increased with $\mathrm{DBH}$, but this effect was significant only after r-value was accounted for in the model. The best model (as indicated by the lowest Akaike information criterion value of 102.1) contained only MPB r-value ( $\mathrm{R})$ and top height $(\mathrm{H})$ as predictive variables (see Equation 1).

\section{(1) Severity $\%=5.742 \mathrm{R}+5.454 \mathrm{H}-144.761$ $(\mathrm{R}$-square $=0.734)$}

As shown in Table 1, Tukey HSD (honestly significant difference) tests for least square mean differences in severity percent between stands indicated that stands fell into three non-overlapping severity groups: $\mathrm{A}, \mathrm{B}$, and $\mathrm{C}$, which contained 11,2, and 4 PSPs respectively. The grouping was the same whether attack severity was assessed in terms of number of stems or basal area per ha. Table 3 shows levels of attack severity percent averaged for each group.

\section{Stand dynamics}

The dynamics assessed and described here are primarily focused on the effects of attack severity on the mortality, falldown, growth and ingress of lodgepole pine trees observed since initial attack of the 17 studies stands. Table 3 shows means and standard deviations for mortality, fall-down and growth, of the three distinct severity groups described above and in Table 1.

Table 4 summarizes results for the statistical significance of severity percent effects on mortality, growth and ingress of lodgepole pine ( $Y$-variables). The bolded Prob $>F$ values in the $X_{1}$ column indicate where the null hypothesis (that severity has no effect on the Y-variable) was untrue. The analysis also took into account pre-attack site and stand conditions. Mortality percent was closely related to attack severity percent (S), as shown in Equation 2.

(2) Mortality $\%=0.8301 S+14.0301$

$(\mathrm{R}$-square $=0.9605)$ 
Table 2. Effects of stand and site variables on attack severity lodgepole pine trees

\begin{tabular}{|c|c|c|c|c|c|c|}
\hline \multicolumn{2}{|c|}{ Regressors } & \multicolumn{3}{|c|}{ Whole model tests } & \multicolumn{2}{|c|}{ Effect tests Prob $>F^{2}$} \\
\hline $\mathrm{X}_{1}$ & $\mathrm{X}_{2}$ & R-square ${ }^{1}$ & Prob $>F^{2}$ & $\mathrm{AIC}^{3}$ & $\mathrm{X}_{1}$ & $\mathrm{X}_{2}$ \\
\hline r-value ${ }^{4}$ & - & 0.6205 & 0.0002 & 106.2 & $0.0002+$ & - \\
\hline Years & - & 0.5443 & 0.0007 & 109.3 & $0.0007+$ & - \\
\hline Basal area & - & 0.2936 & 0.0247 & 116.7 & $0.0247+$ & - \\
\hline Top height & - & 0.2520 & 0.0400 & 117.7 & $0.0400+$ & - \\
\hline Site index & - & 0.2469 & 0.0425 & 117.8 & $0.0425+$ & - \\
\hline $\mathrm{DBH}$ & - & 0.1596 & 0.1122 & 119.7 & 0.1122 & - \\
\hline Density & - & 0.0429 & 0.4248 & 121.9 & 0.4248 & - \\
\hline Age & - & 0.0035 & 0.8204 & 122.6 & 0.8204 & \\
\hline r-value & Top height & 0.7337 & $<.0001$ & 102.1 & $0.0002+$ & $0.0286+$ \\
\hline r-value & Site index & 0.7220 & 0.0001 & 102.9 & $0.0002+$ & $0.0402+$ \\
\hline r-value & $\mathrm{DBH}$ & 0.7167 & 0.0001 & 103.2 & $0.0001+$ & $0.0467+$ \\
\hline r-value & Years & 0.6962 & 0.0002 & 104.4 & $0.0192+$ & 0.0829 \\
\hline r-value & Stems ha ${ }^{-1}$ & 0.6949 & 0.0002 & 104.4 & $<.0001+$ & 0.0860 \\
\hline r-value & Age & 0.6382 & 0.0008 & 107.3 & $0.0002+$ & 0.4218 \\
\hline r-value & Basal area & 0.6335 & 0.0009 & 107.6 & $0.0029+$ & 0.4193 \\
\hline
\end{tabular}

${ }^{1} \mathrm{R}$-square = proportion of the variation in attack severity $\%$ attributed to the included variables.

${ }^{2}$ Prob $>F=$ significance probabilities for the F-ratio for whole models $\left(y=\beta_{0}+\beta_{1} x_{1}+\beta_{2} x_{2}\right)$ and individual effects.

${ }^{3} \mathrm{AIC}=$ Akaike information criterion (lower scores indicate a superior fit).

${ }^{4} \mathrm{r}$-value $=$ local MPB productivity index

${ }^{5}$ Years $=$ years since attack.

${ }^{6} \mathrm{DBH}=$ quadratic mean diameter breast-height.

Table 3. Attack severity percent and post-attack mortality and growth of lodgepole pine trees averaged by severity group

\begin{tabular}{|c|c|c|c|c|c|c|c|c|}
\hline \multirow[b]{2}{*}{ Variable } & \multicolumn{2}{|c|}{ Group A } & \multicolumn{2}{|c|}{ Group B } & \multicolumn{2}{|c|}{ Group C } & \multicolumn{2}{|c|}{ Total } \\
\hline & Mean & $S D$ & Mean & $S D$ & Mean & $S D$ & Mean & $S D$ \\
\hline Attack severity \% stems & 79.7 & 4.4 & 40.7 & 3.2 & 2.7 & 0.9 & 57.0 & 33.7 \\
\hline Mortality \% stems & 80.7 & 5.3 & 35.9 & 6.4 & 17.4 & 3.6 & 60.6 & 29.1 \\
\hline Mortality \% basal area & 87.8 & 4.3 & 35.4 & 5.0 & 13.3 & 3.3 & 64.1 & 33.9 \\
\hline Fall-down\% stems & 3.98 & 2.18 & 7.09 & 4.48 & 4.34 & 3.32 & 4.43 & 2.70 \\
\hline Growth DBH (cm) & 0.59 & 0.23 & 1.06 & 0.24 & 1.18 & 0.36 & 0.78 & 0.37 \\
\hline Growth height $(\mathrm{m})$ & 0.05 & 0.69 & 1.15 & 0.59 & 0.50 & 0.27 & 0.29 & 0.69 \\
\hline Growth basal area $\left(\mathrm{m}^{2} \mathrm{ha}^{-1}\right)$ & 0.29 & 0.19 & 1.96 & 0.20 & 2.78 & 0.24 & 1.07 & 1.14 \\
\hline
\end{tabular}

Table 4. Effects of severity percent and added regressor terms on mortality, growth and ingress of lodgepole pine trees

\begin{tabular}{|c|c|c|c|c|c|c|c|c|c|}
\hline \multirow[b]{3}{*}{ Y-variable } & \multirow[b]{3}{*}{$\begin{array}{c}\text { Attack } \\
\text { severity \% } \\
\left(X_{1}\right)\end{array}$} & \multicolumn{8}{|c|}{ Added regressor $\left(\mathrm{X}_{2}\right)$} \\
\hline & & \multirow[b]{2}{*}{ r-value } & \multirow[b]{2}{*}{$\begin{array}{c}\text { Years } \\
\text { since } \\
\text { attack }\end{array}$} & \multicolumn{6}{|c|}{ Pre-attack condition } \\
\hline & & & & $\begin{array}{c}\text { Site } \\
\text { index }\end{array}$ & $\begin{array}{c}\text { Basal } \\
\text { area ha }\end{array}$ & $\begin{array}{c}\text { Top } \\
\text { height }\end{array}$ & Age & $\mathrm{DBH}$ & $\begin{array}{c}\text { Stems } \\
\text { ha }^{-1}\end{array}$ \\
\hline Mortality\% stems & $<.0001+$ & 0.3582 & 0.9812 & 0.5607 & 0.3602 & 0.5447 & 0.8616 & 0.544 & 0.2894 \\
\hline Mortality\% basal area & $<.0001+$ & 0.4219 & 0.0892 & 0.6592 & 0.3857 & 0.6713 & 0.9861 & 0.6565 & 0.3672 \\
\hline Fall-down\% stems & 0.6247 & 0.1824 & 0.6346 & 0.0867 & 0.7340 & 0.0649 & 0.4556 & $0.0437-$ & 0.0657 \\
\hline Growth DBH (cm) & $0.0006-$ & 0.8110 & 0.5435 & $0.0016+$ & 0.7970 & $0.0057+$ & 0.7728 & $0.0159+$ & $0.0088-$ \\
\hline Growth height (m) & 0.1134 & 0.1529 & 0.3309 & 0.9463 & 0.1433 & 0.7413 & 0.3733 & 0.8182 & 0.5024 \\
\hline Growth basal area ha-1 & $<.0001$ & 0.4513 & 0.6640 & 0.0727 & 0.7214 & 0.0672 & 0.6542 & 0.0940 & 0.1132 \\
\hline Ingress stems $\mathrm{ha}^{-1}$ & 0.8984 & 0.3704 & 0.3928 & 0.3769 & 0.9864 & 0.3484 & 0.7018 & 0.2108 & 0.2742 \\
\hline Ingress basal area ha- ${ }^{-1}$ & 0.8290 & 0.3949 & 0.2999 & 0.3090 & 0.9726 & 0.2928 & 0.7317 & 0.2042 & 0.2705 \\
\hline
\end{tabular}

Values shown are the significance probabilities (Prob $>$ F) for F-ratios obtained by testing individual effects in the model $y=\beta_{0}+\beta_{1} x_{1}+\beta_{2} x_{2}$ (where $\beta_{0}, \beta_{1}$, and $\beta_{2}$ are estimated parameters) 
MPB productivity, years since attack, and pre-attack stand conditions had no significant effect when added to the model. Fall-down showed no significant relationship to attack severity, and a slight negative response to pre-attack DBH. Diameter and basal area growth declined with attack severity. No other effects on basal area growth were significant when included in the model with severity. $\mathrm{DBH}$ growth showed a positive response to site index and pre-attack tree size, and a negative response to stand density, when these variables were included in the model with severity percent.

Ingress of lodgepole pine trees was negligible (see Table 5), and showed no significant trends with attack severity, years since attack, or pre-attack conditions. Ingress of hardwoods (trembling aspen and black poplar) and black spruce was irregular, averaged less than 20 trees per ha, and showed no significant relationship with attack severity. Ingress of shade tolerant conifers (white spruce and balsam fir combined) increased with attack severity percent, in terms of both trees and basal area ha ${ }^{-1}$ (probabilities of chance occurrence less than 0.02). Pre-attack densities and basal areas of hardwoods, spruces and fir were not significant when included in the models predicting ingress of the species as a function of attack severity.

There were insufficient data to examine the effect of attack severity percent on non-tree vegetation. However, changes between the baseline and post-attack measurements were examined by matched pairs analysis. No significant changes were detected in the percent cover of tall shrubs (shrub species $>2.5 \mathrm{~m}$ in height) or ground mosses and lichens. Low shrubs species ( 0.3 to $2.49 \mathrm{~m}$ tall), ground shrubs $(<0.29 \mathrm{~m}$ tall), herbs (non-graminoid, non-woody vascular plant species), and grasses (graminoid species, including grasses, sedges and rushes) all showed statistically significant increases in percent cover following disturbance.

\section{Post-attack stand structure}

Fig. 1 shows mean post-attack densities of trees, saplings, and regeneration as measured 6 to 10 years after initial MPB attack, averaged for all 17 stands across the full range of attack severity. Standard error bars indicate the variability between stands, which is particularly high for regeneration in the white spruce / balsam fir species group. Species groups are as listed in Table 6 . Note the very infrequent occurrence of lodgepole pine seedlings and saplings.

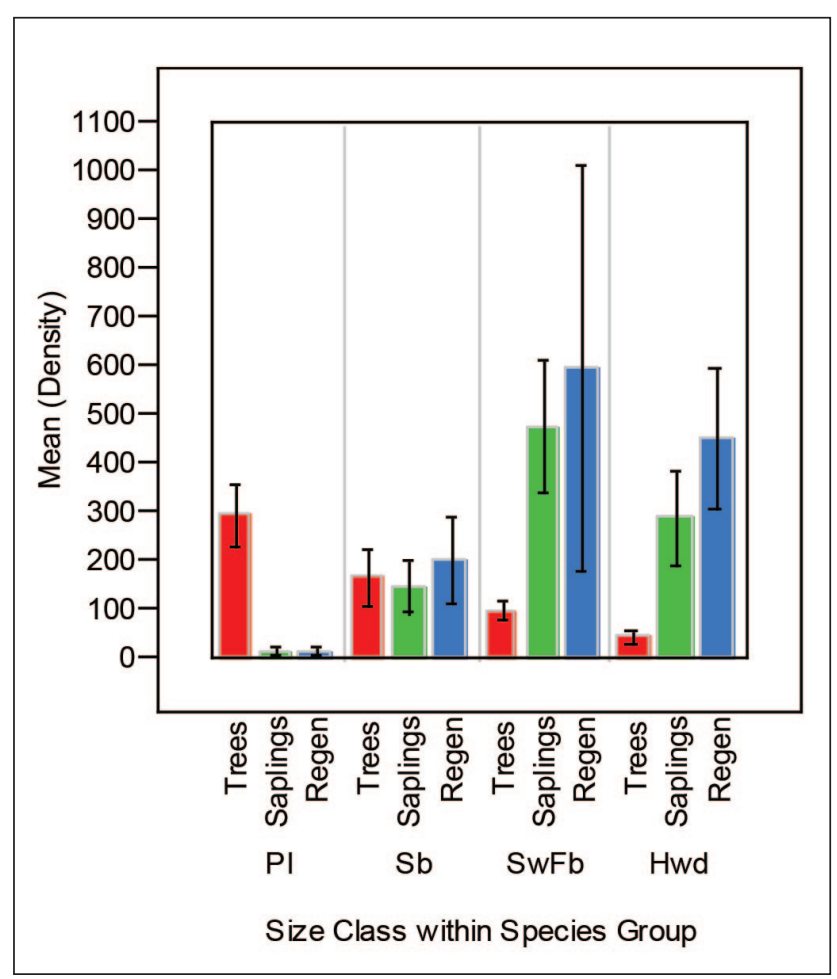

Fig. 1 Mean post-attack densities by size class within lodgepole pine, black spruce, white spruce/balsam fir, and hardwood species groups.

Table 6 summarises statistical significance of the relationships between attack severity and post-attack densities. The bolded Prob $>F$ values in the Severity\% column indicate where the null hypothesis (that severity has no effect on postattack density) was untrue, after taking pre-attack density into account. Tree and total densities of lodgepole pine decreased with attack severity, reflecting the MPB-induced mortality described previously. Tree density of the white spruce / balsam fir species group increased with severity, consistent with the ingress result reported above. No statistically significant trend between attack severity and densities of saplings or seedlings was found for any species. Densities of black spruce saplings and hardwood regeneration were

Table 5. Post-attack tree ingress averaged by species and attack severity groups

\begin{tabular}{|c|c|c|c|c|c|c|c|c|c|}
\hline \multirow[b]{2}{*}{ Variable } & \multirow[b]{2}{*}{ Species } & \multicolumn{2}{|c|}{ Group A } & \multicolumn{2}{|c|}{ Group B } & \multicolumn{2}{|c|}{ Group C } & \multicolumn{2}{|c|}{ Total } \\
\hline & & Mean & $S D$ & Mean & $S D$ & Mean & $S D$ & Mean & $S D$ \\
\hline \multirow[t]{4}{*}{ Density(trees ha $\left.^{-1}\right)$} & Lodgepole pine & 0.45 & 1.00 & 3.04 & 4.30 & 0.00 & 0.00 & 0.65 & 1.62 \\
\hline & Black spruce & 10.11 & 7.16 & 42.74 & 42.86 & 4.59 & 5.83 & 12.65 & 16.94 \\
\hline & White spruce/ fir & 85.16 & 68.68 & 9.13 & 12.91 & 9.00 & 11.35 & 58.29 & 66.24 \\
\hline & Hardwoods & 6.15 & 10.08 & 0.00 & 0.00 & 3.41 & 6.83 & 4.78 & 8.77 \\
\hline \multirow[t]{4}{*}{ Basal area $\left(\mathrm{m}^{2} \mathrm{ha}^{-1}\right)$} & Lodgepole pine & 0.00 & 0.01 & 0.03 & 0.04 & 0.00 & 0.00 & 0.01 & 0.01 \\
\hline & Black spruce & 0.10 & 0.07 & 0.36 & 0.39 & 0.03 & 0.04 & 0.11 & 0.15 \\
\hline & White spruce/ fir & 0.88 & 0.74 & 0.08 & 0.11 & 0.07 & 0.09 & 0.60 & 0.71 \\
\hline & Hardwoods & 0.05 & 0.08 & 0.00 & 0.00 & 0.03 & 0.05 & 0.04 & 0.07 \\
\hline
\end{tabular}


Table 6. Effect of attack severity on post-attack densities of trees, saplings and regeneration of lodgepole pine, black spruce, white spruce/balsam fir and hardwoods, taking into account pre-attack tree densities

\begin{tabular}{|c|c|c|c|c|c|}
\hline \multirow[b]{2}{*}{ Species group } & \multirow[b]{2}{*}{$\begin{array}{l}\text { Y-variable (post- } \\
\text { attack density) }\end{array}$} & \multicolumn{2}{|c|}{ Whole model tests } & \multicolumn{2}{|c|}{ X-variables: Prob $>F$} \\
\hline & & R-square & Prob $>F$ & Severity\% & $\begin{array}{l}\text { Trees ha-1 } \\
\text { pre-attack }\end{array}$ \\
\hline \multirow[t]{4}{*}{ Lodgepole pine (Pl) } & Trees ha-1 & 0.9387 & $<.0001$ & $<.0001$ & $<.0001$ \\
\hline & Saplings ha-1 & 0.1110 & 0.4387 & 0.2267 & 0.5240 \\
\hline & Regen ha ${ }^{-1}$ & 0.1156 & 0.4233 & 0.3601 & 0.2696 \\
\hline & Total stems ha ${ }^{-1}$ & 0.9368 & $<.0001$ & $<.0001$ & $<.0001$ \\
\hline \multirow[t]{4}{*}{ Black spruce (Sb) } & Trees ha-1 & 0.9749 & $<.0001$ & 0.2385 & $<.0001$ \\
\hline & Saplings $\mathrm{ha}^{-1}$ & 0.5711 & 0.0027 & 0.5256 & 0.0091 \\
\hline & Regen $\mathrm{ha}^{-1}$ & 0.1784 & 0.2526 & 0.9961 & 0.1856 \\
\hline & Total stems ha ${ }^{-1}$ & 0.6254 & 0.001 & 0.7416 & 0.0026 \\
\hline \multirow{4}{*}{$\begin{array}{l}\text { White spruce/balsam } \\
\text { fir }(\mathrm{SwFb})\end{array}$} & Trees ha ${ }^{-1}$ & 0.5480 & 0.0066 & 0.0150 & 0.0066 \\
\hline & Saplings $\mathrm{ha}^{-1}$ & 0.0323 & 0.7946 & 0.8214 & 0.5234 \\
\hline & Regen $\mathrm{ha}^{-1}$ & 0.1264 & 0.7211 & 0.1965 & 0.7211 \\
\hline & Total stems ha ${ }^{-1}$ & 0.0779 & 0.5670 & 0.3756 & 0.5973 \\
\hline \multirow[t]{4}{*}{ Hardwoods (Hwd) } & Trees ha-1 & 0.9658 & $<.0001$ & 0.4925 & $<.0001$ \\
\hline & Saplings $\mathrm{ha}^{-1}$ & 0.0761 & 0.5746 & 0.9613 & 0.3102 \\
\hline & Regen $\mathrm{ha}^{-1}$ & 0.3608 & 0.0436 & 0.1674 & 0.0178 \\
\hline & Total stems $\mathrm{ha}^{-1}$ & 0.3707 & 0.0391 & 0.2974 & 0.0130 \\
\hline
\end{tabular}

Results shown are based on the model $y=\beta_{0}+\beta_{1} x_{1}+\beta_{2} x_{2}$, where $y=$ post-attack stems ha- ${ }^{1}, x_{1}=$ attack severity percent, and $x_{2}=$ pre-attack trees ha- ${ }^{1}$

Prob $>\mathrm{F}=$ significance probabilities of the F-ratio for whole model and individual effects

related to pre-attack tree densities. In the white spruce / balsam fir group neither saplings nor regeneration showed any significant density trend with pre-attack tree density.

Dropped pine cone densities increased with severity, averaging $14000 \mathrm{ha}^{-1}$ in high severity stands (i.e., Tukey HSD severity group A in Table 1), compared $6000 \mathrm{ha}^{-1}$ when averaged across the low severity groups B and C. Arboreal cones were still closed on the majority of standing dead and live trees (on average $60 \%$ and $71 \%$ following high and low attack severity respectively). Overall only $2 \%$ of trees were observed to have more than $5 \%$ of their cones open. Serotiny of dropped cones was checked in only four stands, but in these stands only about $2 \%$ of dropped cones were open. Seed viability was not assessed.

\section{Projected growth and yield}

Two disturbance scenarios, "attack" and "no attack", were simulated by MGM for each of the 17 studied stands, and projected for five decades into the future. The "attack" scenario was projected using the actual post-attack stand conditions to initialize MGM. The "no attack" scenario was projected by instead using pre-attack conditions to initialize the model. Table 7 summarizes the results of repeat measures analyses of variance designed to test for differences in projected tree volumes and densities between the two attack scenarios, how these differences vary over time, and whether these responses are related to actual attack severity percent. The bolded values in the Prob $>F$ column for the Disturbance effect and Time ${ }^{*}$ Disturbance interaction indicate where the null hypothesis (that attack has no effect on the long term growth and yield) is untrue. The significance probabilities indicate that projected density and volume differences are related, not only to the disturbance scenario, actual attack severity percent, and time, but also to interactions between these variables. Visualization of these interactions is assisted for volume yields by the bar charts in Fig. 2. For this purpose, stands are grouped into two categories of actual attack severity: "high" (Tukey HSD severity group A in Table 1), and "low" (groups B and C). The differences between volume projections with and without attack are minor for stands within the low attack severity category, and major in the high category. This effect is reflected by the significant interaction between disturbance and severity percent in Table 6 . The relatively high coniferous volumes in stands with no attack, or low levels of attack severity, are projected to decline as the stands age. In stands that have been subject to high levels of actual attack, the lower volumes show some recovery following disturbance, increasing from average volumes of about $80 \mathrm{~m}^{3} \mathrm{ha}^{-1} 10$ years after attack, to over 130 $\mathrm{m}^{3} \mathrm{ha}^{-1}$ after 50 years. These trend differences are reflected by the significant interaction between time, severity and disturbance indicated in Table 6 .

The MGM simulations described above were based on trees only. Projections initialized from post-attack stand conditions were repeated, with sapling and regeneration added to the tree inputs. Table 8 summarizes the results of repeat measures analyses of variance testing for differences in tree volume yields projected with and without the inclusion of seedlings and regeneration. The significant interaction between time and projection method indicate the null hypothesis (that saplings and regeneration will not contribute to future growth and yield) to be untrue. The table indicates statistically significant effects of severity percent and time, and also interactions between these variables and the projection method. Again, visualization of these interactions 
Table 7. Repeat measures analysis of MGM projections for effects of MPB disturbance, attack severity percent and time since attack on future coniferous density and volume

\begin{tabular}{|c|c|c|c|c|c|c|}
\hline Variable & Test & Effect & F statistic & Num DF & Den DF & Prob $>F$ \\
\hline \multirow{7}{*}{$\begin{array}{l}\text { Density } \\
\left(\text { stems ha }^{-1}\right)\end{array}$} & \multirow[t]{3}{*}{ Between stands } & Disturbance & 10.200 & 1 & 30 & 0.0033 \\
\hline & & Severity\% & 20.980 & 1 & 30 & $<.0001$ \\
\hline & & Severity\%*Disturbance & 3.600 & 1 & 30 & 0.0674 \\
\hline & \multirow[t]{4}{*}{ Within stands } & Time & 35.965 & 4 & 27 & $<.0001$ \\
\hline & & Time ${ }^{\star}$ Disturbance & 54.365 & 4 & 27 & $<.0001$ \\
\hline & & Time ${ }^{\star}$ Severity $\%$ & 12.316 & 4 & 27 & $<.0001$ \\
\hline & & Time ${ }^{\star}$ Severity $\%{ }^{\star}$ Disturbance & 4.705 & 4 & 27 & 0.0052 \\
\hline \multirow{7}{*}{$\begin{array}{l}\text { Volume } \\
\left(\mathrm{m}^{3} \mathrm{ha}^{-1}\right)\end{array}$} & \multirow[t]{3}{*}{ Between stands } & Disturbance & 151.726 & 1 & 30 & $<.0001$ \\
\hline & & Severity\% & 26.411 & 1 & 30 & $<.0001$ \\
\hline & & Severity\%^Disturbance & 65.632 & 1 & 30 & $<.0001$ \\
\hline & \multirow[t]{4}{*}{ Within stands } & Time & 24.970 & 4 & 27 & $<.0001$ \\
\hline & & Time ${ }^{\star}$ Disturbance & 11.037 & 4 & 27 & $<.0001$ \\
\hline & & Time ${ }^{\star}$ Severity $\%$ & 9.097 & 4 & 27 & $<.0001$ \\
\hline & & Time ${ }^{\star}$ Severity $\%{ }^{\star}$ Disturbance & 4.508 & 4 & 27 & 0.0064 \\
\hline
\end{tabular}

Num DF = numerator degrees of freedom

$\mathrm{Den} \mathrm{DF}=$ denominator degrees of freedom

is assisted by the bar charts, and by grouping stands into high and low attack severity categories. Fig. 3 shows the positive effect of augmenting tree-only inputs in stands with high attack severity. Mean total volumes $\mathrm{ha}^{-1}$ increase from about $90 \mathrm{~m}^{3}$ at 10 years after attack to $200 \mathrm{~m}^{3}$ after 50 years. This represents a periodic annual increment rate of $2.8 \mathrm{~m}^{3} \mathrm{ha}^{-1}$ per year. The effect is less in stands with low attack severity; but here augmentation reverses the negative trend of volume with time shown when only trees are projected.

\section{Discussion}

MPB attack severity following the 2006 outbreak in western Alberta, as monitored on attacked permanent sample plots in the Lower Foothills natural sub-region, was highly variable. Severity was closely related to MPB productivity, but also affected by top height, DBH and site index. The sampled stands were representative of the prevalent site, stand, and age-class conditions of fire-origin lodgepole pine growing in the Alberta Lower Foothills. The sample size and range of stand and site factors permitted only a limited assessment of factors affecting attack severity. Fortunately, MPB productivity, indexed by $r$-value, has already been extensively monitored in Alberta, and a study covering a wide range of stand and climatic conditions was carried out to support its prediction (Carroll et al. 2017). The analysis successfully modelled variables influencing beetle productivity, including DBH and temperature effects related to elevation and latitude. It thus provides an important tool for predicting attack severity.

Post-attack measurements and 50-year projections of stands with low attack levels indicated little MPB impact, with coniferous volume yields averaging more than $90 \%$ of those projected assuming no attack (see Fig. 2). At high attack levels, total live coniferous volumes 10 years after attack averaged less than $100 \mathrm{~m}^{3} \mathrm{ha}^{-1}$, and less than $20 \%$ of pre-attack values. At 8 to 10 years after attack much of the dead wood was still standing (as predicted by Lewis and Hrinkevich (2013) for the Alberta Foothills region based primarily on low sap-rot incidence), perhaps suggesting a fairly long win-

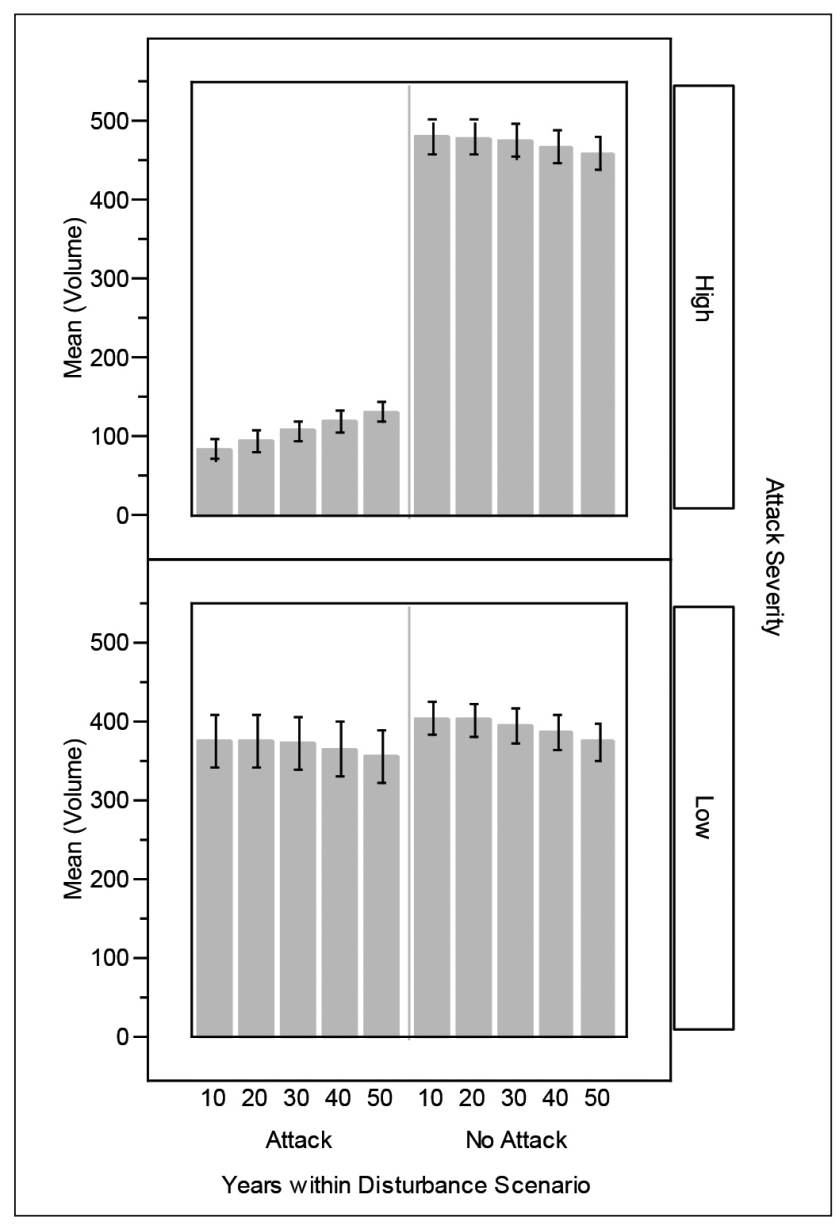

Fig. 2 Mean live coniferous tree volumes (total stem volumes $\mathrm{m}^{3}$ ha-1) projected by MGM for stands subjected to "high" and "low" levels of attack. Projections are shown with attack (based on post-attack plot measurements) and with no attack (simulated from pre-attack measurements]. Error bars indicate standard errors about the means. 
Table 8. Repeat measures analysis of MGM simulations projecting future coniferous volume with and without allowing for contribution of saplings and regeneration

\begin{tabular}{|c|c|c|c|c|c|}
\hline Test & Effect & F statistic & Num DF & Den DF & Prob $>F$ \\
\hline \multirow[t]{3}{*}{ Between stands } & Projection $^{1}$ & 3.697 & 1 & 30 & 0.0640 \\
\hline & Severity $\%$ & 285.345 & 1 & 30 & $<.0001$ \\
\hline & Severity $\%{ }^{\star}$ Projection & 0.017 & 1 & 30 & 0.8975 \\
\hline \multirow[t]{4}{*}{ Within stands } & Time & 8.528 & 4 & 27 & 0.0001 \\
\hline & Time ${ }^{\star}$ Projection & 6.902 & 4 & 27 & 0.0006 \\
\hline & Time ${ }^{\star}$ Severity $\%$ & 6.850 & 4 & 27 & 0.0006 \\
\hline & Time ${ }^{\star}$ Severity $\%{ }^{\star}$ Projection & 2.768 & 4 & 27 & 0.0476 \\
\hline
\end{tabular}

${ }^{1}$ The "projection" input variable has 2 levels: (1) trees-only and (2) trees plus saplings and regeneration suggests that conditions during the first 10 years after attack are unfavourable for pine regeneration, and conditions may only decline in future. Scarcity of suitable seedbeds, considered a major limiting factor for regeneration by McIntosh and Macdonald (2013) in Alberta and Teste et al. (2011) in B.C. will be exacerbated by the increased levels of non-tree vegetative competition observed in our study. Timely natural regeneration of lodgepole pine in such stands cannot be relied upon without management intervention. Areas formerly of pure pine and dow of opportunity for salvage. However, just because the trees are still standing does not necessarily mean they can be milled. Lewis and Hrinkevich (2013) noted that most of the degrade resulted from drying and checking occurred within two to three years of tree mortality, severely limiting utilization for solid wood products thereafter.

Recovery in coniferous growing stock projected over the 50 years following high severity attack was mostly attributable to non-pine species: white spruce, balsam fir and black spruce, with the shade tolerant white spruce / balsam fir species group showing most response. This result is consistent with the Alberta study of Oboite and Comeau (2018), who found a greater response in the release of white spruce than of black spruce. The result also reflects those of Axelson et al. (2018), who found that 30 years after MPB attack in southern Alberta lodgepole pine was no longer the dominant overstorey species and was almost totally absent from understories. Where non-pine species are present in pine-leading stands, reasonable levels of timber productivity may be achieved without management intervention. In the event of widespread attack precluding all stands from being salvaged, it may be prudent to retain such stands and focus management on stands with high attack severity and low levels of non-pine composition. We found no correlation in the shade tolerant species between post-attack sapling / regeneration densities and pre-attack tree densities. This suggests that recognition of stands with non-pine coniferous potential would require inventory techniques, such as light detection and ranging (LiDAR) (Wulder et al. 2008), capable of detecting species below the main canopy.

Pine saplings and seedlings were infrequent in most of the stands measured up to 10 years after disturbance. This result is consistent with other Alberta studies by McIntosh and Macdonald (2013) and Steinke (2019). It is possible that we may have underestimated the eventual contribution of pine regeneration, because only seedlings greater than $30 \mathrm{~cm}$ in height were included in our projections. Ingress of some portion of the regeneration, even under ideal post-fire or postharvest conditions, may be delayed beyond 10 years (Johnstone 1976). Unopened cones present on the ground and in standing trees may also potentially support more ingress. However, we consider the contributions of delayed regeneration doubtful. The role of unopened cones is made questionable by unknown levels of present and future seed degradation, predation and viability. The low level of ingress to date lacking incidental non-pine tree species will require some combination of mechanical site preparation, seeding, planting, or burning in order to restore tree cover.

High levels of variation in MPB attack severity and tree species composition will, in the absence of clearcutting or burning, result in increased diversity in stand and forest

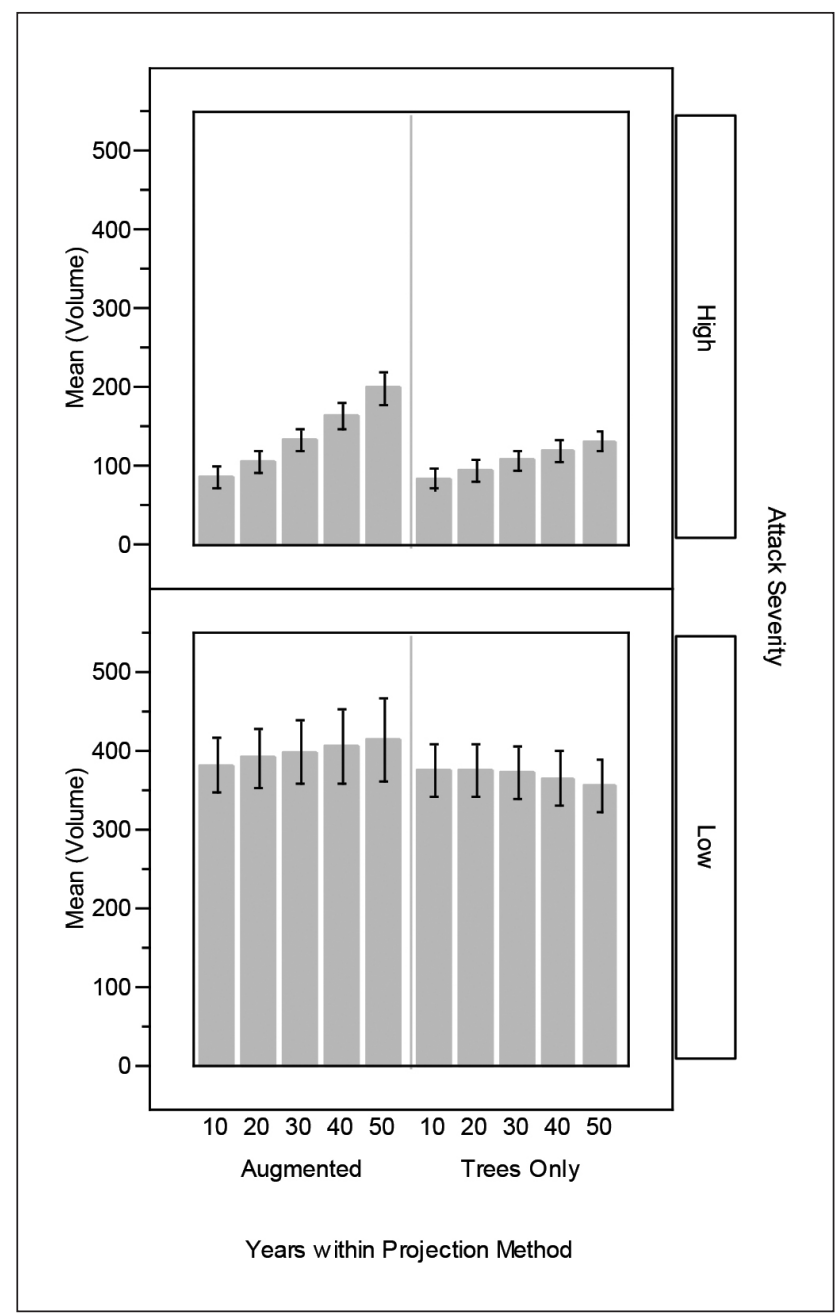

Fig. 3 Effect of augmenting tree-only inputs with data for saplings and regeneration on mean live coniferous tree volumes (total stem volumes $\mathrm{m}^{3} \mathrm{ha}^{-1}$ ] projected by MGM. 
structure. Visualizations of three MGM stand projections at 30 years after disturbance illustrate this in Fig. 4. The figure shows one stand in which no attack is simulated, and two stands with more than $50 \%$ of pine attacked, of which one has low, and the other high, levels of non-pine advanced growth and regeneration. The variation in residual structure, regeneration period, composition and density, will create a somewhat uneven-aged forest type that may be better managed as an irregular shelter-wood system (with the MPB attack substituting for the initial regeneration felling), than by conventional large-scale clearcutting. Benefits of a shelter-wood approach to management would include flexibility in harvest scheduling, increased ecological diversity, and retention of the best trees for meeting mid-term timber supply requirements, whilst at the same time encouraging regeneration and maintaining forest cover. These advantages would need to be weighed against possible disadvantages. In Alberta, planning and implementation of the approach could be impeded by a lack of suitable growth and yield information, and limited by current reforestation policies (Alberta Agriculture and Forestry 2020). More generally recognized disadvantages of the irregular shelter-wood system are: favouring of shade tolerant spruce and fir against shade intolerant pine, reductions in long-term increment (relative to that of even-aged pine stands), damage to the young crop during felling and extraction of timber, and cost increases resulting from diffusion of operations and added difficulties of supervision and control (Troup 1952).

\section{Conclusions}

A wide range in the growth and yield of stands disturbed by MPB in the Lower Foothills is likely over the 50 years following initial attack. Impacts will vary from minor and inconsequential stand modifications to full stand replacement. Our results have implications for the planning of salvage and restoration operations aimed at minimizing losses in longterm timber yield. We suggest that stands should be prioritized for salvage in the following order.

1. Stands with high levels of attack severity, and no or insignificant content of non-pine species. Satisfactory natural regeneration is unlikely within timescales consistent with timber management objectives. If salvage and conventional reforestation (such as some combination of site preparation and planting) are not possible where more than half of the trees are attacked, prescribed burning may be the only alternative for restoring timber production.

2. Stands with high levels of attack severity, but which contain secondary timber species in the main canopy or understorey. Timber production will be naturally restored to some degree, without management intervention. The degree will vary with site conditions and particularly with the amount and composition of non-pine advance growth and regeneration. The level of production restored may not be sufficient to meet timber supply objectives without some level of active management (such as site preparation, seeding and / or enrichment planting of gaps). The resulting species and age mixtures could necessitate a shift from the current regular clear-cutting system to irregular shelter-wood management.

3. Stands with low levels of attack severity. Where less than half the trees are attacked, reduction in timber yield attributable to MPB may be low or inconsequential.
Active management will not always be necessary to maintain satisfactory levels of timber productivity.

The proposed prioritization is primarily applicable if the scale of MPB infestation exceeds, or is likely to exceed, the capacity of companies to salvage all attacked stands. It obviously would be subject to constraints imposed by cost, access and manufacturing considerations. Good stand-specific information will be required to support its implementation. The level of attack severity will need to be known for operational planning, and predicted for longer-term management planning purposes. Forest inventories to support planning should include assessment of understories. Silvicultural management systems, and growth models used in timber supply planning, will need to be adapted or extended to address the more uneven-aged and variable stand structures emerging as a result of MPB attack.

\section{Acknowledgements}

Financial and technical support for this study was provided by the sponsoring members of the Forest Growth Organization of Western Canada (FGrOW) Foothills Pine Project Team: Alberta Newsprint Company, Blue Ridge Lumber Inc., Canfor, Edson Forest Products, Millar Western, Spray Lake Sawmills, Sundre Forest Products, Hinton Wood Products, and Weyerhaeuser Company, in part with funding from the Forest Resources Improvement Association of Alberta. Additional funding was provided by the fRI Research Mountain Pine Beetle Ecology Program. Technical assistance in the application of growth models was provided by Mike Bokalo and Kirk Johnson of the University of Alberta for MGM, and Gyula Gulyas for GYPSY. We gratefully acknowledge the contributions of our project collaborators at the Alberta Ministry of Agriculture and Forestry: Brooks Horne, John Stadt, Ken Stadt, and Caroline Whitehouse; and especially thank Ken Stadt for making available to us the Ministry's permanent sample plot data.

\section{References}

Alberta Agriculture and Forestry. (2020). Reforestation standard of Alberta. Edmonton, Alberta: Department of Agriculture and Forestry, Forestry Division, Forest Management Branch. 361pp.

Amoroso, M.M., K.D. Coates and R. Astrup. (2013). Stand recovery and self-organization following large-scale mountain pine beetle induced canopy mortality in northern forests. For. Ecol. Manage. 310: 300-311. doi:10.1016/j.foreco.2013.08.037.

Anon. (2015). Minimum standards and suggested protocols and priorities for establishing and measuring permanent sample plots in Alberta. Edmonton: Alberta Environment and Sustainable Resource Development and Alberta Forest Growth Organization. Technical Report Pub. No:T/605. 53 pp.

Axelson, J.N., B.C. Hawkes, L. Van Akker and R.I. Alfaro. (2018). Stand dynamics and the mountain pine beetle - 30 years of forest change in Waterton Lakes National Park, Alberta, Canada. Can. J. of Forest Res. 48: 1-12. doi:10.1139/cjfr-2018-0161.

Beckingham, J.D., I.G. Corns and J.H. Archibald. (1996). Field guide to ecosites of west-central Alberta. Special Report 9. Canadian Forest Service, Northwest Region, Northern Forestry Centre, Edmonton, Alberta.

Bokalo, M., K.J. Stadt, P.G. Comeau and S.J. Titus. (2013). The validation of the Mixedwood Growth Model (MGM) for use in forest management decision making. Forests 4: 1-27. doi:10.3390/ f4010001.

Campbell, E.M. and J.A. Antos. (2015). Advance regeneration and trajectories of stand development following the mountain pine bee- 

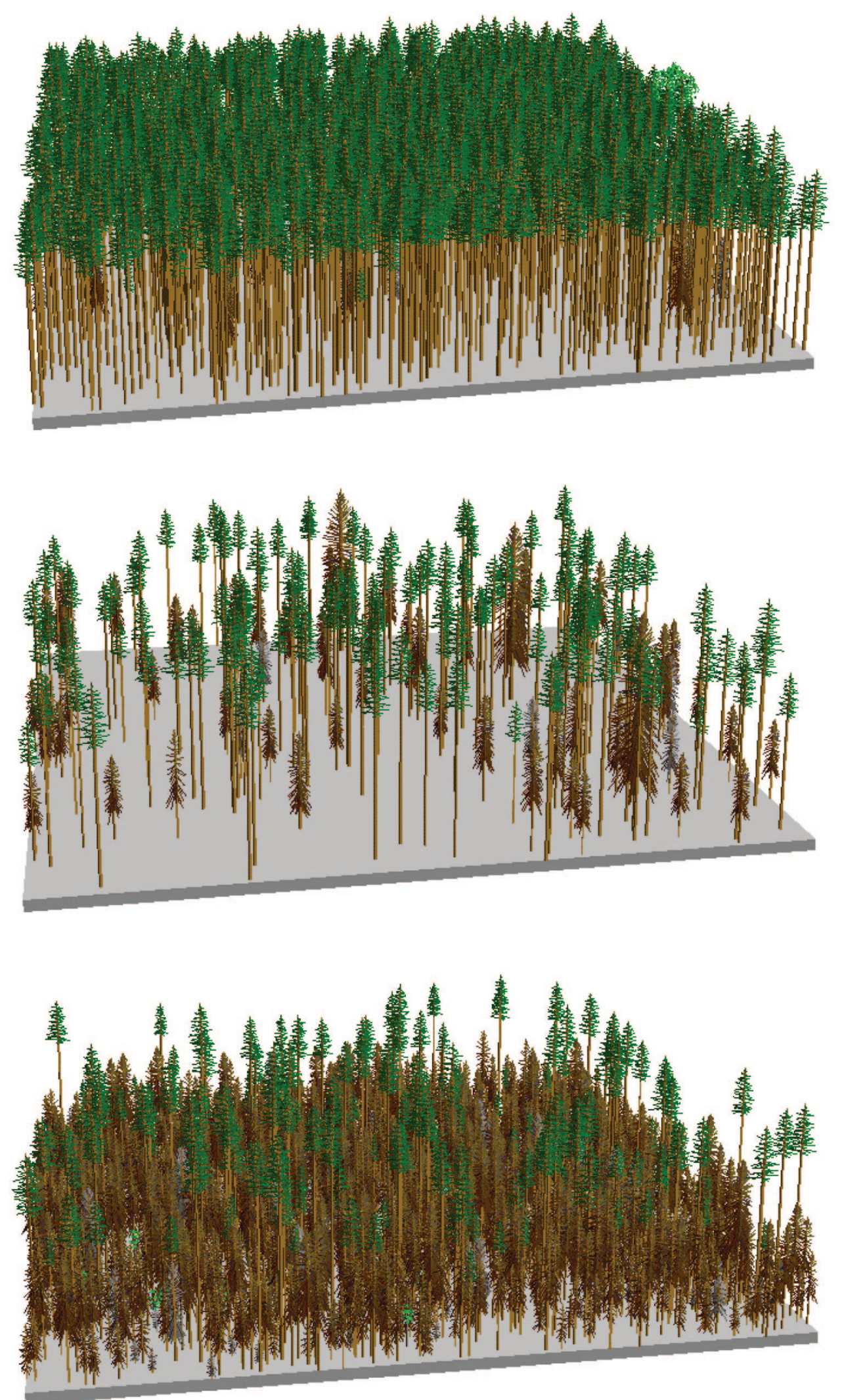

Fig. 4 Visualizations of live stand structure in stand with no attack (top), 30 years after attack in stand with little advanced growth or regeneration (middle), and 30 years after attack in stand with high level of non-pine advanced growth and regeneration (bottom). Nonpine coniferous species are shown in brown. 
tle outbreak in boreal forests of British Columbia. Can. J. Forest Res. 45 (10): 1327-1337. doi:10.1139/cfir-2015-0104.

Carroll, A., B. Seely, C. Welham and H. Nelson. (2017). Assessing the effectiveness of Alberta's forest management program against the mountain pine beetle. Final report for fRI Project 246.18 parts 1 and 2. Foothills Research Institute, Hinton, Alberta. 53 pp.

Coates, K.D. and P.J. Burton. (1997). A gap-based approach for development of silviculturalsystems to address ecosystem management objectives. For. Ecol. Manage. 99: 337-354. doi:10.1016/ S0378-1127(97)00113-8.

Dempster, W.R. (2017). Impact of climate on juvenile mortality and Armillaria root disease in lodgepole pine. Forest. Chron. 93(2): 148-160. doi:10.5558/tfc2017-021.

Dempster, W.R. and S. Meredith. (2014). A discussion of best management practices for reforestation following harvesting of lodgepole pine in the Alberta Foothills. Forest. Chron. 90 (6): 763 770. doi:10.5558/tfc2014-148.

Dhar, A. and C.D.B. Hawkins. (2011). Regeneration and growth following mountain pine beetle attack: A synthesis of knowledge. BC J. Ecosyst. Manage. 12 (2): 1-16.

Dhar, A., L. Parrott and C.D.B. Hawkins. (2016). Aftermath of mountain pine beetle outbreak in British Columbia: Stand dynamics, management response and ecosystem resilience. Forests 7 (8): 171. doi:10.3390/f7080171.

Hawkins, C.D.B., A. Dhar, A., N.A. Balliet and K.D. Runzer. (2012). Residual mature trees and secondary stand structure after mountain pine beetle attack in central British Columbia. For. Ecol. Manage. 277: 107-115. doi:10.1016/j.foreco.2012.04.023.

Huang, S., S. Meng and Y. Yang. (2009). A growth and yield projection system (GYPSY) for natural and post-harvest stands in Alberta. Alberta Sustainable Resource Development Technical Report Pub. No. T/216. 22 pp.

Huang, S., R.A. Monserud, T. Braun, H. Lougheed and O. Bakowsky. (2004). Comparing site productivity in mature fire-origin and post-harvest juvenile lodgepole pine stands in Alberta. Can. J. Forest Res. 34: 1181-1191. doi:10.1139/x04-009.

Johnstone, W.D. (1976). Ingress of lodgepole pine and white spruce regeneration following logging and scarification in west-central Alberta. Environ. Can., Can. For. Serv., North. For. Res. Cent., Edmonton, Alberta. Information Rep. NOR-X-170. 12 pp.

Landhäusser, S.M. (2009). Impact of slash removal, drag scarification and mounding on lodgepole pine cone distribution and seedling regeneration after cut-to-length harvesting on high elevation sites. Forest Ecol. Manag. 258: 43-49. doi:10.1016/j.foreco. 2009.03.045.
Lewis, K.J. and K. Hrinkevich. (2013). Post mortality rate of wood degradation and tree fall in lodgepole pine trees killed by mountain pine beetle in the foothills and central mixedwood regions of Alberta. Final report for the Foothills Research Institute, Hinton, Alberta. 16 pp.

McGaughey, R.J. (2018). Stand Visualization System. Pacific Northwest Research Station, USDA Forest Service. Available online: http://forsys.cfr.washington.edu (accessed on 17 February 2020).

McIntosh, A.C.S. and S.E. Macdonald. (2013). Potential for lodgepole pine regeneration after mountain pine beetle attack in newly invaded Alberta stands. For. Ecol. Manage. 295: 11-19.

Mitchell, J. (2005). Review and synthesis of regeneration methods in beetle-killed stands following mountain pine beetle (Dendroctonus ponderosae) attack: A literature review. In: Mountain Pine Beetle Initiative Working Paper 2005-16. Natural Resources Canada, Canadian Forest Service, Victoria, BC, 25 pp.

Oboite, F.O. and P.G. Comeau. (2019). Release response of black spruce and white spruce following overstory lodgepole pine mortality due to mountain pine beetle attack. For. Ecol. Manage. 432: 446454. doi:10.1016/j.foreco.2018.09.029.

Powell, J.M. (1966). Distribution and outbreaks of Dendroctonus ponderosae in forests of Western Canada. Canadian Department of Forestry, Information Report A-X-2, Forest Research Laboratory, Calgary, Alberta. 19 pp.

Steinke, J. (2019). Beyond beetle: natural regeneration after MPB attack in lodgepole pine forests of west-central Alberta. fRI Research Quicknote, Foothills Research Institute, Hinton, Alberta. www.friresearch.ca. 2 pp.

Teste, F.P., V.J. Lieffers and S.M. Landhausser. (2011). Seed release in serotinous lodgepole pine forests after mountain pine beetle outbreak. Ecol. Appl. 21: 150-162. doi:10.1890/09-1881.1.

Troup, R.S. (1952). Silvicultural systems. $2^{\text {nd }}$ edition. Oxford University Press, London W.1. 216 pp.

SAS Institute Inc. (2002). Statistics and graphics guide, version 5. Cary, NC. 707 pp.

Wulder, M.A., C.W. Bater, N.C. Coops, T. Hilker and J.C. White. (2008). The role of LiDAR in sustainable forest management. Forest. Chron. 84(6): 807-826. doi:10.5558/tfc84807-6. 